www.jmscr.igmpublication.org

Index Copernicus Value: 79.54

ISSN (e)-2347-176x ISSN (p) 2455-0450

crossrefDOI: https://dx.doi.org/10.18535/jmscr/v7i2.01

\title{
Study of Operative Management of Proximal Humerus Fracture Treated with Locking Plates at Trauma Center Bikaner, Rajasthan
}

\author{
Authors \\ Surender Kumar Chopra ${ }^{1}$, Sanjay Malhotra ${ }^{2 *}$, Vivek Kumar Bagadia ${ }^{3}$ \\ ${ }^{1}$ Assistant Professor, ${ }^{2,3}$ Resident \\ Trauma Center Sardar Patel Medical College Bikaner \\ *Corresponding Author \\ Sanjay Malhotra \\ Resident, Trauma Center Sardar Patel Medical College Bikaner, India
}

\begin{abstract}
Background: Fractures of the proximal humerus account for $5.7 \%$ of all fractures, with an incidence rate of 63 cases per thousand adult individuals per year.

Methods: Hospital based Observational study conducted at Trauma center Sardar Patel Medical College, Bikaner. 50 patients were included.

Results: The mean time for radiological union was 9.8 weeks (8-12 weeks). At the final follow-up, the mean Constant shoulder score was 82 . The results were excellent in 28 patients, good in 14 patients, fair in 5 patients and poor in 3 patients. Other complications were not symptomatic enough to undergo additional surgery. No cases of Infection, AVN, hardware failure, locking screw loosening or non-union were noted.

Conclusion: Philos plate provides stable fixation in proximal humerus fractures. Additionally, meticulous surgical dissection to preserve vascularity of humeral head is necessary to prevent potential complications such as $A V N$.
\end{abstract}

Keywords: Locking plates, Proximal humerus fracture, Philos.

\section{Introduction}

Fractures of the proximal humerus account for $5.7 \%$ of all fractures, with an incidence rate of 63 cases per thousand adult individuals per year. ${ }^{1}$ Its incidence is increasing due to population ageing and osteoporosis $^{2-3}$. Most proximal humerus fractures are stable, minimally displaced and can be managed conservatively. ${ }^{4}$ The surgical treatment of displaced fracture however remaining a challenge. Non operative management of the more severe fracture is associated with poor results. The large range of operative techniques described (e.g. Kwire, TBW, plating, nailing, arthroplasty) for managing the more complex fracture is a testament to the lack of clear superiority of any one method. ${ }^{5-9}$ Most of these techniques have been associated with complications related to hardware failure, osteonecrosis, nonunion, malunion, rotator cuff impingement. ${ }^{10}$

Proximal humeral locking plates such as proximal humeral interlocking plate (Philos, Synthes, 
Switzerland) offer several potential advantages in the treatment of these injuries. They are site specific, low profile plates. The plate is precontoured for proximal humerus and insertion of locking screws obviates the need for a plate to bone compression preserving the blood supply to the bones. The insertion of multiple polyaxial locking screws through the specific targeting device into humeral head fragment provides a fixed angle support in multiple planes, which should in theory, maintain the reduction achieved, while allowing for early mobilisation. ${ }^{11}$ However inspite of all potential benefits significant level of construct failure and revision surgery with the use of proximal humerus locking plates have been reported particularly in patients over 65 years of age. $^{12,13}$

\section{Materials and Methods}

Study Design: Observational

Study Centre: Trauma center sardar patel medical college, Bikaner.

Duration of the study: 6 Months

Study Sample size: 50 patients.

Data collection: The indications of operative treatment were based on Neer's classification ${ }^{14}$ of proximal humerus fractures. All the adult patients with closed two- and three-part fractures of the proximal humerus, irrespective of age, who reported within 3 weeks of injury were included in the study. In patients with four-part fracture, fixation was performed only when the patients' age was $<60$ years. Patients with open and pathological fractures of the proximal humerus were excluded from the study.

\section{Operative technique}

The patients received prophylactic intravenous antibiotic. All patients were placed in supine position with sandbag under scapula and c-arm was positioned opposite side of the operative site. Deltoid split approach was used. Skin incision may follow the direction of muscle fibers along the upper deltoid at the junction of the anterior and middle thirds. The deltoid is split along its fibers no more than $5 \mathrm{~cm}$ from acromian in order to avoid injury to the axillary nerve. The head fragment when involved was then reduced from its typical varus position through manipulation and flexing of the arm. Once in position, the fracture was then held temporarily with K-wire and the reduction checked fluoroscopically. The Philos plate was then applied lateral to the bicipital groove, 1-2 cm distal to the upper end at the greater tuberosity conventional non locking screw was then inserted into the slotted gliding hole on the plate. When brought the plate to the bone and allowed for minor adjustments in the plate height and position when checked on fluoroscopy. Polyaxial locking screw inserted into the head, locking screw were also inserted into the shaft. ${ }^{15}$

The arm was placed in the sling after wound closure. Only pendulum exercise were permitted for the first four weeks postoperatively with elbow and wrist range of motion also encountered. 4-6 weeks postoperatively passive progressive to active range of motion then started under the guidance of physiotherapist. Postoperative outcome was measured with constant shoulder score at a minimum of 1 year follow up.

\section{Statistical analysis}

Continuous variables were summarised as Mean and Standard Deviation whereas nominal / categorical variables as proportion (\%).

\section{Results}

\section{Socio-demographic variable}

\begin{tabular}{|l|c|c|}
\hline $\begin{array}{l}\text { Socio-demographic } \\
\text { variable }\end{array}$ & $\begin{array}{c}\text { No. of } \\
\text { patients }\end{array}$ & Percentage \\
\hline Gender & & \\
\hline Male & 27 & $54.00 \%$ \\
\hline Female & 23 & $46.00 \%$ \\
\hline Age & \multicolumn{2}{|c|}{$45.6 \pm 7.23$ Yrs } \\
\hline
\end{tabular}

There were 27 males and 23 females with mean age of 45.6 \pm 7.23 years (age ranged 25-90).

\section{Cause of injury}

\begin{tabular}{|l|c|c|}
\hline Cause of injury & No. of patients & Percentage \\
\hline RTA & 38 & 76.00 \\
\hline Fall at home & 12 & 24.00 \\
\hline Total & 50 & 100.00 \\
\hline
\end{tabular}


All fractures were united clinically and radiologically. The mean time for radiological union was 9.8 weeks (8- 12 weeks). At the final follow-up, the mean Constant shoulder score was 82. The results were excellent in 28 patients, good in 14 patients, fair in 5 patients and poor in 3 patients. Other complications were not symptomatic enough to undergo additional surgery. No cases of Infection, AVN, hardware failure, locking screw loosening or non-union were noted.

\section{Result after final follow-up}

\begin{tabular}{|l|c|c|}
\hline Grading & No. of patients & Percentage \\
\hline Excellent & 28 & 56.00 \\
\hline Good & 14 & 28.00 \\
\hline Fair & 5 & 10.00 \\
\hline Poor & 3 & 6.00 \\
\hline
\end{tabular}

\section{Discussion}

Our study implies that treatment of proximal humerus fractures with Philos plate may give a satisfactory outcome. It allows early mobilization as the fixation is usually stable. An improved outcome requires precise knowledge and adequate surgical expertise. In addition, treatments of these fractures are challenging, especially in the elderly. Different techniques have been described for the fixation of comminuted and displaced proximal humerus fractures. ${ }^{16}$ All these techniques have been associated with a varying rate of complications such as cut-out or back-out of the screws and plates, nonunion, AVN, and fracture distal to the plate. ${ }^{17}$

Locking periarticular plate fixation offers more advantages compared to many implants and have been shown to be superior to non-locking plates.

${ }^{18}$ Meticulous care must be taken to preserve the overlying soft tissues during open reduction and internal fixation since damage to these soft tissues may disturb the vascularity of fracture fragments. ${ }^{19}$ In our study, we used the standard deltoid split approach in most of the patients. Important aspects of the surgical technique include placement of the plate in strict adherence to the technique, determination of appropriate length and placement of the screws with fluoroscopy, insertion of screws to the head in adequate number and position, providing medial cortex support for the prevention of varus displacement and to fix tubercle fragments, fixation of the sutures passing through the junction of the tubercle and rotator cuff to the plate. ${ }^{20}$

\section{Conclusion}

Philos plate provides stable fixation in proximal humerus fractures. Additionally, meticulous surgical dissection to preserve vascularity of humeral head is necessary to prevent potential complications such as AVN.

\section{References}

1. Geiger EV, Maier M, Kelm A, Wutzler S, Seebach C, Marzi I. Functional outcome and complications following PHILOS plate fi xation in proximal humeral fractures. Acta Orthop Traumatol Turc. 2010;44(1):1-6.

2. Baron JA, Barrett JA, Karagas MR. The epidemiology of peripheral fractures. Bone. 1996;18(3):209-13.

3. Lanting B, MacDermid J, Drosdowech D, Faber KJ. Proximal humeral fractures: a systematic review of treatment modalities. J Shoulder Elbow Surg. 2008;17(1):42-54.

4. Lee SH, Dargent-Molina P, Breart G. Risk factors for fractures of the proximal humerus: results from the EPIDOS prospective study. J Bone Miner Res. 2002;17(5):817-25.

5. Nguyen TV, Center JR, Sambrook PN, Eisman JA. Risk factors for proximal humerus, forearm, and wrist fractures in elderly men and women: the Dubbo Osteoporosis Epidemiology Study. Am J Epidemiol. 2001;153(6):587-95.

6. Nho SJ, Brophy RH, Barker JU, Cornell $\mathrm{CN}$, MacGillivray JD. Innovations in the management of displaced proximal humerus fractures. J Am Acad Orthop Surg. 2007;15(1):12-26. 
7. Young TB, Wallace WA. Conservative treatment of fractures and fracturedislocations of the upper end of the humerus. J Bone Joint Surg $\mathrm{Br}$. 1985;67(3):373-7.

8. Park MC, Murthi AM, Roth NS, Blaine TA, Levine WN, Bigliani LU. Two-part and three-part fractures of the proximal humerus treated with suture fixation. J Orthop Trauma. 2003;17(5):319-25.

9. Ogiwara N, Aoki M, Okamura K, Fukushima S. Ender nailing for unstable surgical neck fractures of the humerus in elderly patients. Clin Orthop Relat Res. 1996;330:173-80.

10. Resch H, Povacz P, Fröhlich R, Wambacher M. Percutaneous fixation of three- and four-part fractures of the proximal humerus. J Bone Joint Surg Br. 1997;79(2):295-300

11. Robinson CM, Page RS, Hill RM, Sanders DL, Court-Brown CM, Wakefield AE. Primary hemiarthroplasty for treatment of proximal humeral fractures. J Bone Joint Surg Am. 2003;85(7):1215- 23.

12. Sadowski C, Riand N, Stern R, Hoffmeyer $P$. Fixation of fractures of the proximal humerus with the Plant Tan Humerus Fixator Plate: early experience with a new implant. J Shoulder Elbow Surg. 2003;12(2):148-51.

13. Fankhauser F, Boldin C, Schippinger G, Haunschmid C, Szyszkowitz R. A new locking plate for unstable fractures of the proximal humerus. Clin Orthop Relat Res. 2005;430:176-81

14. Björkenheim JM, Pajarinen J, Savolainen V. Internal fixation of proximal humeral fractures with a locking compression plate: a retrospective evaluation of 72 patients followed for a minimum of 1 year. Acta Orthop Scand. 2004;75(6):741-5

15. Constant CR, Murley AH. A Clinical method of functional assessment of the shoulder. Clin Orthop Relat Res. 1987;214:160-4.

16. Siffri PC, Peindl RD, Coley ER, Norton J, Connor PM, Kellam JF. Biomechanical analysis of blade plate versus locking plate fixation for a proximal humerus fracture: comparison using cadaveric and synthetic humeri. J Orthop Trauma. 2006;20(8):54754.

17. Seide K, Triebe J, Faschingbauer M, Schulz AP, Püschel K, Mehrtens G, et al. Locked vs. unlocked plate osteosynthesis of the proximal humerus- a biomechanical study. Clin Biomech. 2007;22(2):176-82.

18. Walsh S, Reindl R, Harvey E, Berry G, Beckman L, Steffen T. Biomechanical comparison of a unique locking plate versus a standard plate for internal fixation of proximal humerus fractures in a cadaveric model. Clin Biomech. 2006;21(10):1027- 31.

19. Papadopoulos P, Karataglis D, Stavridis SI, Petsatodis G, Christodoulou A. Midterm results of internal fixation of proximal humeral fractures with the PHILOS plate. Injury. 2009;40(12):12926.

20. Gardner MJ, Weil Y, Barker JU, Kelly BT, Helfet DL, Lorich DG. The importance of medial support in locked plating of proximal humerus fractures. J Orthop Trauma. 2007;21(3):185-91. 